INTERNATIONAL MONETARY FUND

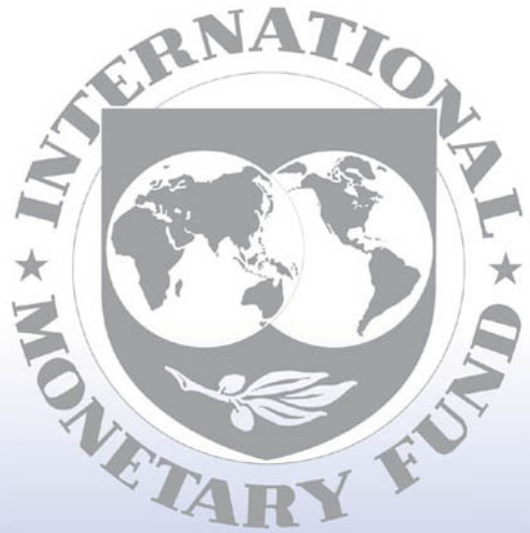

Staff

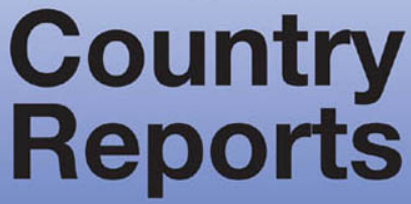




\section{Honduras: Joint Staff Assessment of the Poverty Reduction Strategy Paper Progress Report}

The attached Joint Staff Assessment (JSA) of the Poverty Reduction Strategy Paper Progress Report for Honduras, prepared by the staffs of both the World Bank and IMF, was submitted with the member country's Poverty Reduction Strategy Paper (PRSP) or Interim PRSP (IPRSP) to the Executive Boards of the two institutions. A JSA evaluates the strengths and weaknesses of a country's poverty reduction objectives and strategies, and considers whether the PRSP or IPRSP provides a sound basis for concessional assistance from the Bank and Fund, as well as for debt relief under the Enhanced Heavily Indebted Poor Countries (HIPC) Debt Initiative. The Boards then decide whether the poverty reduction strategy merits such support.

To assist the IMF in evaluating the publication policy, reader comments are invited and may be sent by e-mail to publicationpolicy@imf.org.

Copies of this report are available to the public from

International Monetary Fund $\bullet$ Publication Services

$70019^{\text {th }}$ Street, N.W. $\bullet$ Washington, D.C. 20431

Telephone: (202) 623-7430 • Telefax: (202) 623-7201

E-mail: publications@imf.org •Internet: http://www.imf.org

Price: $\$ 15.00$ a copy

\section{International Monetary Fund} Washington, D.C. 
This page intentionally left blank

(C)International Monetary Fund. Not for Redistribution 


\author{
INTERNATIONAL MONETARY FUND AND \\ INTERNATIONAL DEVELOPMENT ASSOCIATION
}

\author{
HONDURAS
}

\title{
Joint Staff Assessment of the Poverty Reduction Strategy Paper First Annual Progress Report
}

\author{
Prepared by the Staffs of the International Monetary Fund and \\ the International Development Association \\ Approved by Adrienne Cheasty and G. Russell Kincaid (IMF), \\ and David de Ferranti and Gobind Nankani (IDA)
}

February 2, 2004

1. The first Poverty Reduction Strategy Paper (PRSP) Progress Report of the Government of Honduras (GOH) presents a complete review of the government's implementation of the PRSP ${ }^{1}$ to date and updates the PRSP for the period 2004-07. This Progress Report (henceforth the Report) presents the results in the implementation of the PRSP presented to the Boards of the IMF and IDA on October 5, 2001 and October 11, 2001, respectively. The Report incorporates inputs from government, civil society, and the donor community. It addresses four key areas: (i) the consultation process; (ii) progress in poverty reduction; (iii) implementation of policies and programs to date; and (iv) updates to the PRSP with strategic and programmatic areas remaining unchanged ${ }^{2}$ but incorporating a revised medium-term macroeconomic framework; modifying targets and intermediate indicators, policies and programs to support the updated PRSP; and adjusting public sector management measures and monitoring and evaluation.

\footnotetext{
${ }^{1}$ Estrategia de Reducción de la Pobreza, Government of Honduras, July 2001.

${ }^{2}$ The five strategic areas are: (i) prioritization of actions that tend to reduce poverty in a sustainable manner; (ii) prioritization of actions favoring the least developed groups and areas of the country; (iii) strengthening of civil society participation and decentralization in the PRS; (iv) strengthening of governance and participatory democracy within the PRS framework; and (v) reduction of environmental vulnerability and its impact on poverty. The six programmatic areas are: (i) accelerating equitable and sustainable economic growth; (ii) poverty reduction in rural areas; (iii) reducing urban poverty; (iv) investing in human capital; (v) strengthening social protection for specific groups; and (vi) guaranteeing the sustainability of the strategy.
} 


\section{OVERALl ASSESSMENT OF THE REPORT}

2. The Report presents a comprehensive assessment of challenges encountered in implementing the poverty reduction strategy in Honduras. It reports on progress made to date and candidly identifies factors related to less-than-satisfactory PRS implementation. Among these factors the Report details a deterioration of the country's fiscal position and little progress in implementing structural reforms, as evidenced by deviations from economic targets and consequent derailment of the PRGF arrangement at the end of 2001. These policy slippages, combined with a slowdown in growth abroad and declining terms of trade, led to slower-than-expected growth. The Report could have provided a more complete assessment of factors that stalled PRS implementation during 2003 - this reporting lag is expected to be eliminated in the next PRSP progress report.

3. The Report continues to emphasize the original strategic objectives and thus, it maintains the same long-term vision of the PRSP. It identifies challenges, particularly since performance of desired outcomes has been satisfactory for only about one-third of all goals; it revises downward several medium-term targets and intermediate indicators; and continues to link long-term PRS goals to Millenium Development Goals (MDGs). It notes the ongoing work on a Poverty and Social Impact Analyses (PSIA) for analyzing the redistributive impact of the recent tax reform packages.

4. The Report appropriately stresses the need to accelerate implementation of the proposed updates to PRS policies and programs, to ensure steady progress toward medium- and long-term goals. The Report emphasizes the need to maintain a stable macroeconomic and fiscal stance. In this context, the PRS will support an acceleration in equitable and sustainable economic growth, implementation of measures to improve competitiveness, and an increase in the coverage of investments in human capital to continue improving the progressivity of public spending. Linked to the need for a stable macroeconomic and fiscal situation, the Report details policy measures to remove institutional, legal and administrative barriers to economic activity, to strengthen the judicial system and reduce corruption, to improve the efficiency and effectiveness of social sector investments, and to enhance modernization, transparency, and accountability of public administration. In addition, pursuing an effective decentralization of functions from the central government to the municipalities is properly identified by the Report as a key measure to improve targeting of the poor and more responsive public service delivery. The Report details enhanced operational and institutional arrangements to ensure better PRS implementation supported by the Social Cabinet, the Presidential Technical Support Unit (UNAT), the PRS Consultative Council, the PRS Fund, and the Interinstitutional Technical Group (GTI). In particular, participatory monitoring has systematically taken place through the PRS Consultative Council as well as in other consultations with different stakeholders.

5. The Report provides detailed government-led plans to improve donor coordination. The Report emphasizes that the priorities of the $\mathrm{GOH}$ are to maintain a stable macroeconomic and fiscal position and consequently program prioritization needs 
to be aligned to the PRS. The Report establishes the urgent need to realign donor assistance toward achieving the development objectives contained in the updates to the PRS, to improve the impact and cost-effectiveness of programs while reducing administrative costs, and to initiate social auditing mechanisms to ensure that programs and projects translate into tangible and sustainable benefits to the population.

\section{Progress in Implementation of the Poverty Reduction Strategy and UPDATES FOR 2004-07}

\section{A. Consultation Process}

\section{PRSP implementation to date has succeeded in broadening civic} participation, while the government has continued to support the consultation process. The government in coordination with the PRS Consultative Council continued consultations during implementation and preparation of the Report. Workshops took place for governmental sectors in seven topics: macroeconomics and competitiveness; agriculture, food and rural development; human development; road infrastructure; governance and human rights; environment and risk management, and social safety nets. Local governments and civil society also met in nine workshops representing a broad range of stakeholders and incorporating donors, youth and children, women, nongovernmental organizations, local governments, farmers, workers, the Honduran Private Sector Council (COHEP), indigenous groups (Nahoas, Pech, Tawankas, Tolupanes, Lencas, Garífunas y Chortís), and beneficiaries. The PRSP, the Report, and other relevant material to the PRS are posted on the ministry of the presidency website:

http://www.sdp.gob.hn/.

\section{Consultations have significantly raised interest from civil society members in} PRS implementation, monitoring, and evaluation. PRS consultations originally had the purpose of establishing mechanisms to improve dialogue with government and incentives for civil society, the general population, indigenous groups, and the poor to integrate their priorities and demands into the strategy. The process has also had an impact on the design and implementation of the strategy and on the updates to the PRS integrated in the Report. In-depth discussions have addressed the six PRS programmatic areas and specific issues have been raised. In particular, many groups have expressed the need to emphasize private investment and production rather than the social sectors to attain equitable growth and poverty reduction.

\section{Consultations have been substantial, although some groups remain skeptical.}

Some groups present at the consultations criticized elements of the PRSP. They raised concerns over the macroeconomic framework and fiscal measures, fearing these measures could disproportionately impact the poor. Population groups in some regions of the country have also expressed some degree of skepticism with regard to the PRSP process. In particular, they felt that the fuel tax increase was not properly discussed. Nevertheless, many participants expressed concerns about slow PRSP implementation and delays in attaining the Heavily Indebted Poor Countries (HIPC) Initiative completion 
point, urging the government to complete the process. Many other groups criticized the size of the state and supported establishing consistent public sector wage policies vis-àvis macroeconomic constraints. These groups have also advocated in other forums for the elimination of tax exemptions favoring vested interests. In general, most observers agree that the government, supported by the PRS Consultative Council, has made a good-faith effort to follow a participatory approach to prepare the strategy and to strengthen the participatory process during implementation, monitoring, and evaluation of the strategy.

\section{B. Medium-Term Macroeconomic Framework}

\section{The macroeconomic framework agreed with Fund staff for a new PRGF} arrangement for 2004-06 is fully consistent with the framework presented in the Report. The Report considers sound macroeconomic policies and structural reforms as important means of achieving sustainable GDP growth, which in turn is key for poverty reduction. It assumes slightly lower medium-term GDP growth projections than the PRSP ( $4 \frac{1}{2}$ percent versus $5 \frac{1}{2}$ percent for 2006 ), owing to the experienced fiscal slippages in 2002-03, along with a deteriorating external environment and reduced external financing. A central element of the growth strategy is a gradual increase in fiscal savings that will free resources to revitalize the anti-poverty program. This strategy will be complemented by a stable monetary policy, a comprehensive financial sector reform, further trade liberalization (notably the Central American Free Trade Agreement, CAFTA), a revival of private investment from the opening of key sectors to private participation, and the strengthening of institutions and governance.

\section{The medium-term macroeconomic framework centers on fiscal sustainability} and prudent monetary policies. The fiscal strategy seeks to gradually reduce deficits in the combined public sector to $13 / 4$ percent of GDP by 2006 . To this end, the government is expanding the tax base and improving revenue administration. The Report could have further discussed the implications of remaining features of the tax system with potential anti-poverty impacts (such as tax exemptions), and detailed in consequence the future direction of tax policy. In addition, the Report recommends the control of expenditures through a sustainable wage policy and budget cuts of non-priority spending. The deficit will mainly be financed with external resources on concessional terms with a view to ensuring debt sustainability. Monetary policy will seek a gradual decline in inflation, while preserving adequate reserve coverage.

\section{The analysis of the relation between growth and poverty reduction is limited.} Sustainable poverty reduction policies could greatly benefit from an in-depth analysis of poverty dynamics and its relationship with the sectoral and geographic distribution of growth, and changes in the labor market. The Report could have further elaborated on the envisaged strategy for reforming the financial system and its impact on poverty alleviation. IDA and IMF staffs suggest incorporting this analysis into the next PRSP progress report. Particular emphasis should be given to understanding these links in rural areas where the incidence of poverty is highest. Also, the government is encouraged to analyze issues of access to financial services by the poor. Furthermore, in view of the 
Report's envisaged increase of the elasticity between growth and poverty reduction to about one and one half (it averaged two-thirds in the 1990s), a clear outline of the factors behind the targeted reduction in poverty is warranted. It would also be helpful to further analyze ways to improve the income distribution and the impact of growth on lower income levels.

\section{The authorities have made substantial progress in assessing PRS' spending.}

The Report incorporates detailed spending estimates for each of the six programmatic areas in the strategy as well as a functional classification of poverty spending. The Report estimates that the annual overall cost of the strategy will increase from $71 / 2$ percent of GDP in 2003 to $93 / 4$ percent by 2007, of which about 35 to 45 percent of these costs is expected to be covered with external resources (including HIPC debt relief, debt rescheduling, and concessional lending) while the remainder is a domestic effort. A financing gap amounting to about 1 percent of GDP a year is projected to arise in 2006-07.

\section{Poverty Reduction}

\section{Progress in poverty reduction has been disappointingly modest so far.}

Although the target for extreme poverty was met in 2002, this was not the case for the overall poverty target. Moreover, recent preliminary results from the Permanent MultiPurpose Household Survey (EHPM) for May 2003 indicate that both extreme and overall poverty have rebounded upward. The deterioration in the country's fiscal position and slow progress in PRSP implementation, combined with adverse external conditions, have dampened growth, contributed to a fall in GDP per capita, and slowed progress in poverty reduction. Honduras urgently needs to recover lost ground and to steadily implement policies and programs aiming toward the MDGs. The Report clearly identifies this disappointing outcome and the updates to the PRSP incorporate relevant changes to programmatic areas for better prioritization and targeting, decentralization and improved service delivery, public sector management, and realignment of donor assistance. With regards to statistical capacity, the National Institute of Statistics (INE) has continued to improve the systematic analysis of poverty and will enhance poverty measurement next year through the first Living Standard Measurement Survey (LSMS).

\section{Targets and Intermediate Indicators}

\section{Only slightly over a third of the PRSP targets have been met during PRSP} implementation. This disappointing performance is mostly attributable to lower economic growth than originally envisaged and slow PRSP implementation.

Nevertheless, improvements in achieving PRSP targets will also require strengthening work at sectoral levels, in allocating resources according to prioritized actions as well as in strengthening execution capacity. This, together with significant improvements in the fiscal situation, are key challenges for accelerating progress in PRSP targets. 


\section{Some targets are reasonably less ambitious in the medium term and new} indicators have been adopted for equitable growth, while long-term targets aim at meeting the MDGs. The authorities have done a thorough review of performance relative to PRSP targets and indicators and appropriately decided to revise some of the targets downward, such as those for poverty and access to water. Recent progress in reducing overall child malnutrition and maternal mortality rates exceeded PRSP targets and is consequently reflected in a revision upward for them in the Report. The Report also strengthened the definition of intermediate indicators and input indicators, as suggested in the previous JSA (although regional indicators could be developed for the next progress report). Targets for education have been slightly modified, responding to improvements in the measurement of administrative records. Two new indicators have been adopted for equitable growth: coverage of electricity and telephone lines. However, for Honduras to be able to achieve most PRSP/MDG goals, steady progress is needed in several contributing areas. In particular, poverty reduction requires accelerated equitable economic growth and steady PRSP implementation. The elasticity of poverty reduction to economic growth has been very low in Honduras and consequently increasing and improving service delivery is key to broadening the base for distributing the benefits from growth. Given the country's fiscal situation, this needs to be accompanied by measures and incentives for restoring private sector dynamism, particularly of small- and medium-sized enterprises which tend to be labor intensive and have strong backward and forward linkages, and hence high multiplier effects. Although child malnutrition and maternal mortality rates exceeded PRSP targets at the national level, the poorest areas of the country have experienced considerably smaller improvements partly due to poor targeting coupled with low and stagnant program coverage. Thus, improving service delivery would also need to incorporate better effectiveness and efficiency in resource use. The authorities' commitment to implementing updated policy measures in the medium term in three main areas as detailed in the Report should be conducive to attaining updated targets.

\section{E. Policies and Programs}

\section{Three main policy areas have been adequately prioritized for PRSP}

implementation, namely, restoring economic dynamism and employment generation, development of human capital, and justice and personal security. These priorities incorporate cross-cutting emphasis on environmental sustainability and risk prevention, gender equity, and decentralization. In this area, initial steps are underway and the GOH has expressed its intention to deconcentrate public service delivery in the medium-term. Thus, the Report could have provided a brief description of the decentralization strategy. In particular, the planned steps to devolve spending responsabilities to municipalities, strengthen their implementation capacity, and improve expenditure control at the local government level. The process of prioritization, led by the authorities, has been enriched by the consultations coordinated by the PRS Consultative Council with participation of government, civil society, and donors in sectoral working groups. While this prioritization rightly addresses major bottlenecks to PRSP implementation, emphasis is 
also needed in the modernization of the public administration, in particular public sector financial management and procurement.

\section{However, effective implementation of the strategy needs to consolidate initial} efforts to establish operational links with PRSP goals. The Social Cabinet, in coordination with UNAT and other line ministries and government agencies responsible for implementing the strategy, has initiated a process of translating PRSP intermediate indicators into specific actions and measurable outputs with detailed timelines and funding allocation commitments. The process of policy prioritization needs to continue advancing to effectively use the national budget strategically for implementing specific priority actions. Restoring economic growth and fiscal discipline are needed for successful PRSP implementation, but these measures need to be accompanied by steady progress in sectoral actions in those areas appropriately prioritized to ensure attainment of PRSP targets which may include program redesign, consolidation, and/or elimination.

\section{The Central American Free Trade Agreement (CAFTA) is a significant} opportunity for enhancing economic prospects in Honduras. Since the United States is Honduras' major trading partner, CAFTA is expected to: (i) boost exports by making permanent and expanding the Caribbean Basin Initiative trade preferences currently enjoyed by Honduran exporters; (ii) improve the investment climate and thus attract new national and foreign investment; and (iii) consolidate the Central American Common Market trading block. Honduras faces important challenges in the implementation of CAFTA, including the need to cushion the potential impact on a few sensitive protected activities (mainly traditional agricultural activities) and ensuring that the gains from freer trade benefit the majority of the population. IDA is supporting a Central America-wide regional study on CAFTA, which includes Honduras, to be completed by mid-2004 and to be followed by a regional study on trade facilitation. Another challenge for Honduras in relation to CAFTA is its potential impact on public finances. Although the authorities believe that Honduras' generally low levels of external tariffs, and the expected gradual reduction of tariffs over a period of up to 20 years, should result in a low short-term fiscal impact, nonetheless IDA and IMF staffs suggest a more in-depth analysis of this area once liberalization schedules are publicly available, and the incorporation of the results in the next PRSP progress report.

\section{F. Public Expenditure Management}

19. In 2002, the authorities created a Poverty Reduction Fund (FRP) ${ }^{\mathbf{3}}$ to keep track of the fiscal savings resulting from HIPC relief and to monitor the channeling of those savings toward poverty reducing activities (Decree 70-2002). The operating guidelines for this fund are accessible on SEFIN's website:

http://www.sefin.gob.hn/reglamentofrp.htm. The FRP operates as an actual fund, consisting of several special accounts at the Central Bank of Honduras (BCH). The

${ }^{3}$ Fondo para la Reducción de la Pobreza (FRP). 
system is adequate to track the flow of HIPC resources under the narrow definition of poverty-reducing spending adopted in the Honduras PRSP, completed in $2001 .^{4}$

\section{The definition of poverty-reducing spending has been expanded by the}

authorities with this Report. This decision is supported by the staffs because it permits establishing a more accurate link between poverty-reducing spending and poverty outcomes. The expanded definition of poverty spending requires a more comprehensive tracking system that clearly identifies the evolution of overall poverty-reducing and nonpoverty-reducing spending in total public spending. The current tracking system needs to be reinforced to allow for monitoring of overall public spending on poverty-reducing programs that are designed to achieve certain poverty outcomes, and to track the source and use of all FRP funds including HIPC debt relief (by contrast, the current narrow tracking system limits its sight to spending financed exclusively from HIPC relief). To improve the tracking system, the Fund has assisted the authorities to identify specific steps that could be taken during 2004 (including full automation of anti-poverty spending) while the World Bank and IDB have been assisting in upgrading the system over the medium term. Thus, the Integrated Public Financial Admnistration System (SIAFI) would allow for the tracking of the expanded definition of anti-poverty spending. Public spending information from the central government as well as decentralized agencies will soon be available online. In addition, a complete version of the Country Financial Accountability Assessment (CFAA), also jointly supported by the World Bank and the IDB, has already been distributed. Implementation of CFAA recommendations would receive financial and technical support through an IDA PRS Technical Assistance Credit currently under preparation.

21. The FRP framework will be reformed to render it more compatible with the expanded definition of poverty-reducing spending. ${ }^{5}$ The authorities have indicated to IDA their intentions to replace the poverty fund by a 'virtual' fund, similar to those used in other HIPC countries. Virtual funds track poverty spending through the 'tagging' of specific expenditures in the budget. ${ }^{6}$ The tagging has already been incorporated into the 2004 budget proposal and the necessary reforms to the corresponding legislation are currently being prepared. The authorities have been advised that an adequate mechanism for tracking the budgetary savings from HIPC debt relief must be operating satisfactorily to IDA before Honduras can be considered for the HIPC Completion Point.

\footnotetext{
${ }^{4}$ The Government of Honduras' First PRSP Progress Report (paras. 96-99) presents the amounts and uses of interim HIPC relief received by Honduras during 2000-03 on the basis of the current tracking mechanism.

${ }^{5}$ Ibidem, para. 194.

${ }^{6}$ Virtual and poverty funds are compared in the Joint World Bank-IMF paper on "Tracking of Poverty-Reducing Spending in Heavily Indebted Poor Countries (HIPCs),” March 27, 2001.
} 


\section{G. Monitoring and Evaluation}

\section{Important efforts have been made to design a national system for monitoring} PRSP indicators, the System of PRS Indicators (SIERP). These are significant initial steps toward establishing a good and accessible baseline and targeting tool for the PRSP. However, SIERP requires systematization and dissemination for wider use to effectively contribute to the formulation, execution, and monitoring and evaluation of programs and indicators at the national, regional, departmental, and local levels. Systematization would need to incorporate the use of recent and upcoming sources of census and survey data plus administrative records to ensure frequent updates and periodic monitoring. The upcoming first LSMS can be an excellent opportunity to generate a poverty targeting map by combining this information with the population census. In addition, SIERP needs to promote improvements in the quality and use of administrative data at the sectoral levels which can prove useful to monitor progress in intermediate indicators. It is critical for SIERP to integrate recent updates and revisions to PRSP indicators and targets contained in the Report. ${ }^{7}$ The system also needs to be made fully consistent with initial efforts coordinated by the Social Cabinet and UNAT to establish operational links with PRSP goals. The staffs attach particular importance to a well-functioning PRSP monitoring system, regard it as a core responsibility of the government, and encourage the authorities to dedicate further efforts to ensure updating and effective use of SIERP's information in policy making, program selection, and monitoring and evaluation.

\section{A PSIA of key relevance for distributive policies has been initiated on tax}

reform. An area of reform with important economic, social, and political impact for PSIA work is the tax reform packages approved by congress in 2002 . The analysis is integrated into the government's monitoring and evaluation efforts of PRS policies and programs. The PSIA work on tax reform has been initiated by the World Bank in close coordination with UNAT, with technical and financial support provided by the Bank. The staffs suggest incorporating the results of this analysis in the next PRSP progress report. This PSIA will determine the redistributive impact of the tax reform on both vertical and horizontal equity. ${ }^{8}$ The analysis will also explore implementation, such as tax compliance (which is an area currently receiving support from U.S. AID), and complementary measures to suggest ways to maintain neutrality or slight progressivity of taxation and complementary measures for progressive public spending. The staffs suggest incorporating the results of this analysis in the next PRSP progress report. Two other PSIAs are under consideration in coordination with UNAT, one on the public investment program and another on public social service delivery.

\footnotetext{
${ }^{7}$ Government of Honduras. First PRSP Progress Report. Table V.1.

${ }^{8}$ Vertical equity implies that those with greater ability to pay taxes should contribute a larger proportion of their income or wealth in taxes. Horizontal equity implies those with equal ability to pay taxes should pay the same proportion in taxes.
} 


\section{H. Risks to the Strategy}

\section{In the staffs' view, the strategy continues to be subject to several important political, institutional, economic, and environmental risks.}

- $\quad$ The authorities gathered necessary support to obtain congressional approval of a new wage policy framework. To implement the PRSP, they will need to continue sustaining this momentum in order to strengthen support for economic reform by such actions as continuing the national dialogue and implementing the government's communication strategy.

- Important institutional risks to program implementation are posed by weaknesses in government financial management, the judiciary, the supreme audit agency, and executing line ministries. IDA's CAS contemplates technical and financial assistance for institution building in all lending scenarios, and IDA is currently undertaking work on fiduciary assessments, public sector management, and judicial reform.

- $\quad$ The economy faces significant vulnerabilities in its public finances, including from potential political difficulties in fully implementing all of the government's expenditure-rationalization and revenue-enhancing measures. In particular, pressures from public sector labor unions and demands on non poverty-reducing spending constitute substantial risks to the fiscal program. The government will also need to ensure that the decentralization process is consistent with improved efficiency of public spending and does not lead to additional fiscal pressure. The government needs to develop fiscal contingency plans incorporating scenarios with lower-than-envisaged concessional financing and the potential impact of the financial sector reform currently underway. The PRGF program agreed with IMF staff and the Bank and IDB's programmatic budgetary support loans will provide close monitoring, identify early warning signs, and assist the authorities in implementing fiscal contingency measures.

- The fragilities of the financial system could pose significant risks to the PRS. The government will need to implement as planned its financial system reform to adequately address the vulnerabilities identified in the 2003 FSAP.

- While growth projections appear attainable in light of the economic and structural policies set out in the Report slippages in program implementation as well as worse-than-expected external conditions and natural disasters could result in lower growth and slower poverty reduction.

25. These risks are not evaluated by the Report. The staffs recommend that the authorities: (i) incorporate the analysis of these risks into the next PRSP progress report, detailing action plans to mitigate and/or avoid them and outlining the measures envisaged to address possible fiscal slippages and to improve the economy's resilience to external 
shocks, and (ii) begin implementation to increase the likelihood of attaining PRSP/MDG goals.

\section{Conclusion}

\section{The Report presents a coherent medium-term macroeconomic framework} and credible efforts toward implementing the poverty reduction strategy, particularly in light of the updates to the PRSP. Higher growth rates than the historical trend will be necessary to reach most MDGs set for 2015. The staffs underscore the need for continued prudent macroeconomic policies, complemented by structural reforms to raise the competitiveness of the economy. Sustained macroeconomic stability and broadbased economic growth continue to be key elements for achieving policy objectives and strategy targets.

\section{The authorities have made important progress in addressing PRSP} implementation difficulties. Progress has been made in several areas, namely in: (i) reaching agreement, ad referendum, on a PRGF program supported by the IMF and working toward attaining critical prior actions, such as the congressional approval of the wage law; (ii) reviewing PRSP implementation and making the appropriate updates to policies, targets, and programmatic priorities through a participatory process consulting key stakeholders; (iii) significant improvements are being adopted by SIAFI, although further efforts are needed in financial management and procurement; and (iv) initiating a PSIA on the tax reform.

\section{The staffs consider, however, that satisfactory implementation of the PRSP} targets within the revised macroeconomic framework still needs to be established. In addition, work is needed in several areas to ensure sustained progress in the future, and advancement in their implementation should be provided in the next progress report, especially in: (i) consolidating macroeconomic stability and reducing the fiscal deficit through a combination of revenue and expenditure measures, while simultaneously achieving the poverty-reducing spending targets agreed in the program; (ii) improving accountability and transparency in fiscal and public financial and procurement systems; (iii) implementing program prioritization at the sectoral levels, and applying impact and cost-effectiveness criteria; (iv) pursuing government-led efforts to realign donor assistance to support the PRSP; and (v) consolidating the national system of monitoring indicators.

\section{In sum, in the view of the staffs of the World Bank and the IMF, Honduras'} Poverty Reduction Strategy continues to articulate a sound set of policies and programs. However, there has been only limited progress in implementation since completion of the PRS due to a combination of policy slippages and exogenous shocks. Nevertheless, in light of continued reforms and policy commitments, the staffs consider that the strategy continues to provide a credible framework for World Bank and Fund concessional assistance. The staffs recommend that the respective Executive Directors of the World Bank and the IMF reach the same conclusion. 